\title{
Lung CD8+ T cells in COPD have increased expression of bacterial TLRs
}

\author{
Christine M Freeman ${ }^{1,2^{*}}$, Fernando J Martinez ${ }^{2}$, MeiLan K Han², George R Washko, Jr. ${ }^{3}$, Alexandra L McCubbrey ${ }^{4}$, \\ Stephen W Chensue ${ }^{4,5,7}$, Douglas A Arenberg ${ }^{2}$, Catherine A Meldrum², Lisa McCloskey ${ }^{2}$ and Jeffrey L Curtis $2,4,6$
}

\begin{abstract}
Background: Toll-like receptors (TLRs) on T cells can modulate their responses, however, the extent and significance of TLR expression by lung T cells, NK cells, or NKT cells in chronic obstructive pulmonary disease (COPD) is unknown.

Methods: Lung tissue collected from clinically-indicated resections ( $n=34)$ was used either: (a) to compare the expression of TLR1, TLR2, TLR2/1, TLR3, TLR4, TLR5, TLR6 and TLR9 on lung CD8+ T cells, CD4+ T cells, NK cells and NKT cells from smokers with or without COPD; or (b) to isolate CD8+ T cells for culture with anti-CD3 $\varepsilon$ without or with various TLR ligands. We measured protein expression of IFN- $\gamma$, TNF- $a, I L-13$, perforin, granzyme A, granzyme $B$, soluble FasL, CCL2, CCL3, CCL4, CCL5, CCL11, and CXCL9 in supernatants.

Results: All the lung subsets analyzed demonstrated low levels of specific TLR expression, but the percentage of CD8+ T cells expressing TLR1, TLR2, TLR4, TLR6 and TLR2/1 was significantly increased in COPD subjects relative to those without COPD. In contrast, from the same subjects, only TLR2/1 and TLR2 on lung CD4+ T cells and CD8+ NKT cells, respectively, showed a significant increase in COPD and there was no difference in TLR expression on lung CD56+ NK cells. Production of the Tc1 cytokines IFN- $\gamma$ and TNF-.alpha; by lung CD8+ T cells were significantly increased via co-stimulation by Pam3CSK4, a specific TLR2/1 ligand, but not by other agonists. Furthermore, this increase in cytokine production was specific to lung CD8+ T cells from patients with COPD as compared to lung CD8+ T cells from smokers without COPD.
\end{abstract}

Conclusions: These data suggest that as lung function worsens in COPD, the auto-aggressive behavior of lung CD8+ T cells could increase in response to microbial TLR ligands, specifically ligands against TLR2/1.

Keywords: Chronic obstructive pulmonary disease, CD8+ T cells, Toll-like receptors, Lung

\section{Background}

Chronic obstructive pulmonary disease (COPD), the $3^{\text {rd }}$ leading cause of death in the United States, is a chronic, debilitating disease with a rapidly increasing incidence [1]. Although COPD is recognized to have important systemic manifestations [2], its principal pathological changes occur in the lungs and include irreversible lung destruction, airways remodeling, mucus hypersecretion, and inflammatory cell infiltration [3]. This infiltration is characterized by increased numbers of macrophages,

\footnotetext{
* Correspondence: cmfreema@med.umich.edu

${ }^{1}$ Research Service, Department of Veterans Affairs Healthcare System, Ann Arbor, MI 48105, USA

${ }^{2}$ Division of Pulmonary \& Critical Care Medicine, Department of Internal Medicine, University of Michigan Health System, Ann Arbor, MI 48109, USA Full list of author information is available at the end of the article
}

neutrophils, and CD8+ T cells in the lungs. CD8+ T cells have been implicated in COPD pathogenesis primarily because their numbers in lung parenchyma and small airways correlate inversely with forced expiratory volume in one second $\left(\mathrm{FEV}_{1}\right)[4,5]$, the modality most frequently used to define COPD severity. We have previously shown that lung CD8+ T cell mRNA transcripts for IFN- $\gamma$, perforin, and granzyme B correlate inversely to $\mathrm{FEV}_{1} \%$ predicted [6,7]. Based on the ability of CD8+ T cells to kill cells that they recognize as infected or damaged, and to secrete cytokines that can recruit and activate additional inflammatory cells, CD8+ T cells have considerable potential to damage lung parenchyma. Nevertheless, despite support in murine models $[8,9]$, there is no direct evidence that human lung CD8+ $\mathrm{T}$
C Biomed Central 
cells mediate such damage in COPD and it is unclear what mechanisms drive this amplified CD8 response in the minority of smokers who develop COPD.

The function of lung CD4+ T cells, natural killer (NK) cells and natural killer $\mathrm{T}$ (NKT) cells in COPD has been less widely studied. There is evidence that numbers of CD4+ T cells and NK cells, but not of NK T cells, also increase in the lung as the disease progresses $[3,10,11]$. In peripheral blood, the cytotoxic effector function of NK and NKT cells appears to be impaired and their relative number to be reduced in COPD subjects $[12,13]$. However, the same investigators later demonstrated that NK and NKT cells collected from the sputum were both higher as a proportion of all leukocytes and more cytotoxic in COPD subjects than in healthy smokers or nonsmoking healthy subjects [14]. A similar finding was also very recently reported for NK and NKT cells in the bronchoalveolar lavage fluid from individuals with COPD [15]. As NK and NKT cells can be a potent source of cytokines and cytotoxic molecules, an increase in their number or improper effector function could contribute to COPD pathology.

Recent data from both human and murine studies have revealed that Toll-like receptors (TLRs), originally described on innate immune cells, also modulate $\mathrm{T}$ cell responses. mRNA for TLR1, TLR2, TLR3, TLR4, TLR5, TLR7 and TLR9 has been detected in human peripheral blood $\mathrm{T}$ cells, although at greatly varying levels [16]. Engagement of TLRs on T cells lowered the activation threshold for co-stimulatory signals delivered by antigenpresenting cells [16-18]. TLR3 and TLR9 stimulation enhanced the survival of activated murine CD4+ T cells, without augmenting their proliferation [18]. IFN- $\gamma$ production was increased by stimulation via TLR3 or TLR4 in human CD8+ T cells $[19,20]$ and via TLR5 or TLR7/8 in human cells positive for CD45RO, which would consist predominately of memory $\mathrm{T}$ cells [16]. Evidence also suggests that TLR stimulation of CD8+ T cells enhances their cytotoxicity. Co-stimulating activated $\mathrm{T}$ cells with TLR2 ligands upregulated granzyme B secretion and cytotoxic activity [17]. Furthermore, TLR3 and TLR9 ligands induced fully efficient cytotoxic responses by murine CD8+ $\mathrm{T}$ cells, overriding the requirement for $\mathrm{CD} 4+\mathrm{T}$ cell help [21]. In contrast, a different study found that engagement of TLR3 on human CD8+ T cells had no effect on their cytolytic activity [19]. Human peripheral blood NK cells reportedly express high levels of TLR3, TLR7, and TLR9 and stimulation with ligands led to an increase in IFN- $\gamma$ production [22]. In a mouse model of COPD, NK cells from smoke-exposed mice produced more IFN- $\gamma$ following stimulation with the ligands for TLR3, TLR7, and TLR9 than NK cells from mice exposed to filtered air [23].

By contrast, relatively little is know about the expression of TLRs by lung T cells, NK cells, or NKT cells in
COPD. In endobronchial biopsies, TLR4 and TLR9 expression was increased on CD8 $+\mathrm{T}$ cells of subjects with COPD as compared to control subjects. Stimulation of peripheral blood CD8+ T cells with cigarette smoke condensate led to increases in TNF- $\alpha$ and IL-10, that were attenuated following TLR4 or TLR9 inhibition [24]. However, the role of other TLRs or specific TLR agonists was not explored.

Based on the ongoing colonization of the lower airways in COPD by microbial pathogens, we hypothesize that modulation from TLR signaling could contribute to the exaggerated pathogenic response of lung CD8+ T cells in COPD. To test this hypothesis, we used flow cytometry to analyze TLR expression on lung CD8+ $\mathrm{T}$ cells (CD3+ CD8+ CD56-), CD4+ T cells (CD3+ CD4+ CD56-), NK cells (CD3- CD56+ CD4- CD8-), CD4 NKT cells (CD3+ CD56+ CD4+ CD8-) and CD8 NKT cells (CD3+ CD56+ CD8+ CD4-). After observing increases in the TLR expression on CD8+ $\mathrm{T}$ cells from COPD subjects compared to subjects with normal pulmonary function, we assessed the functional relevance of this expression by stimulating isolated CD8+ T cells with TLR ligands and measuring production of cytokines, cytotoxic molecules, and chemokines. Our data show that human lung CD8+ T cells responded to TLR agonists, in particular the TLR2/1 agonist Pam3CSK4, by increasing production of cytokines and chemokines in response to TCR stimulation.

\section{Methods}

\section{Specimens and patient population}

Consented subjects undergoing clinically-indicated resections for pulmonary nodules, lung volume reduction surgery, or lung transplantation were recruited from the University of Michigan Health System and the VA Ann Arbor Healthcare System. Studies and consent procedures were approved by Institutional Review Boards. All subjects $(n=34)$ gave written consent preoperatively and underwent preoperative spirometry, prospectively collected medication history and clinical evaluation by a pulmonologist. Available non-contrastenhanced CT scans $(n=13)$ were analyzed for percent emphysema using 3D Slicer software (www. airwayinspector.org) at a threshold of $<-950$ Hounsfield units. We categorized subjects using the 2008 classification of the Global Initiative for Chronic Obstructive Lung Disease (GOLD) [25]. Subjects $(n=14)$ with a smoking history of 10 pack years or greater, a ratio of forced expiratory volume in 1 second to forced vital capacity $\left(\mathrm{FEV}_{1} / \mathrm{FVC}\right)>0.70$, normal spirometry, and no clinical diagnosis of COPD represent smoking controls (S). Subjects $(n=20)$ with a smoking history, defined as greater than 10 pack years, $\mathrm{FEV}_{1} / \mathrm{FVC}<0.7$ and abnormal spirometry were considered to have COPD. Table 1 shows the male-to-female ratio, age, smoking history, 
Table 1 Summary of subject demographics, smoking histories, spirometry and emphysema

\begin{tabular}{cccc}
\hline Group & S & COPD & $\boldsymbol{p}$ value \\
\hline Subjects, $\mathrm{n}$ & 14 & 20 & \\
\hline Sex ratio, M/F & $11 / 3$ & $12 / 8$ & $\mathrm{NS}$ \\
\hline Age, years (SD) & $62(9)$ & $62(11)$ & $\mathrm{NS}$ \\
\hline Smoking, pack-years (SD) & $60(29)$ & $62(41)$ & $\mathrm{NS}$ \\
\hline Smoking status (Active/Former) & $6 / 8$ & $5 / 15$ & $\mathrm{NS}$ \\
\hline FEV $1, \%$ pred (SD) & $91(16)$ & $40(27)$ & $<0.0001$ \\
\hline Emphysema,\% (SD) & $12(14)$ & $36(15)$ & 0.02 \\
\hline Surgical indication (resection/LVRS/transplant) & $14 / 0 / 0$ & $8 / 5 / 7$ & 0.001 \\
\hline ICS use (yes/no) & $1 / 13$ & $14 / 6$ & 0.0004 \\
\hline Recent infection (yes/no) & $0 / 14$ & $2 / 18$ & $\mathrm{NS}$ \\
\hline
\end{tabular}

Data are presented as average (SD), except for sex and smoking status ratios. Former smokers were defined as those subjects that had quit smoking for more than 6 months. Subjects were considered to have a recent infection if they had taken a course of antibiotics in the past 6 weeks. S, smoker without COPD; M, male; F, female; LVRS, lung volume reduction surgery; ICS, inhaled corticosteroids; NS, not significant.

$\mathrm{FEV}_{1} \%$ predicted, and\% emphysema for both subject categories. Former smokers were defined as those subjects who had quit smoking for greater than 6 months.

Studies and consent procedures were performed in accordance with the Declaration of Helsinki at the VA Ann Arbor Healthcare System and the University of Michigan Health System and were approved by the Institutional Review Board at each site (FWA 00000348 and FWA 00004969, respectively).

\section{Sample preparation and flow cytometric analysis}

Under the supervision of a Pathologist, in cases of nodule resection, only parenchymal, non-neoplastic lung tissue remote from the nodules and lacking postobstructive changes was collected. In the cases of explanted lungs, tissue from the distal region of the lung was collected. Lung specimens were immediately stored in fresh RPMI and kept at $4^{\circ} \mathrm{C}$ until processed. Lung sections weighing approximately $3 \mathrm{~g}$ were dispersed using a Waring blender without enzyme treatments, which we have previously shown produces single cell suspensions of high viability and functional capacity [6]. Importantly, not all types of experiments were performed on tissue from every subject, due to limitations in the size of some samples.

For flow cytometry, cells were filtered through a $40 \mu \mathrm{m}$ strainer to remove debris and were resuspended in staining buffer (2\% FBS in PBS). Cells were added in a volume of $100 \mu \mathrm{l}$ to each flow tube. We used monoclonal antibodies against the following antigens (clones shown in parentheses): CD45 (HI30), CD3 (UCHT1), CD4 (OKT4), CD8 (OKT8), CD56 (MEM-188), TLR1 (GD2.F4), TLR2 (T2.5), TLR3 (TLR3.7), TLR4 (HTA125), TLR6 (hPer6), TLR9 (eB72-1665), (eBioscience, San Diego, CA), and TLR5 (85B152.5) (Abcam, Cambridge, MA). Appropriate isotype-matched controls were used in all experiments. Antibodies were conjugated to either fluorescein isothiocyanate (FITC), phycoerythrin (PE), phycoerythrin-cyanine 7 (PE-Cy7), allophycocyanin (APC), allophycocyanincyanine 7 (APC-Cy7), Pacific Blue, Alexa Fluor 700, or biotin, with the biotinylated antibodies developed using streptavidin-phycoerythrin-cyanine 5 (SA-PE-Cy5), as shown in Table 2.

To evaluate cell viability by flow cytometry, we used LIVE/DEAD ${ }^{\circledR}$ Fixable Dead Cell Stain Kit (Life Technologies) in Aqua. This reactive dye permeates the membranes of necrotic cells, resulting in positive fluorescent staining. This procedure is also compatible with intracellular staining. Cells were first incubated in the dark with the LIVE/DEAD ${ }^{\circledR}$ Fixable dye for 30 minutes, washed, and then incubated with primary antibodies and secondary reagents for 25 minutes each at room temperature, with washing between incubations. We measured intracellular expression of the endosomal receptors TLR3 and TLR9, after cell fixation and permeabilization. Cells were analyzed on an LSR II flow cytometer (BD Bioscience, San Jose, CA) equipped with $488 \mathrm{~nm}$ blue, $405 \mathrm{~nm}$ violet, $633 \mathrm{~nm}$ red lasers. Data were collected using FACS Diva software with automatic compensation, and were analyzed using FlowJo software (Tree Star, Inc., Ashland, OR). A minimum of 10,000 viable (cells that are negative for the Aqua Live/Dead fluorescence) CD45+ events were collected per sample.

\section{In vitro stimulation}

In separate experiments, CD8+ CD56- $\mathrm{T}$ cells were isolated from lung tissue by sequentially incubating the single-cell suspension with magnetic beads (Miltenyi Biotec, Auburn, CA). Samples were first incubated with CD56 magnetic beads for 15 minutes at $4^{\circ} \mathrm{C}$ and positively selected using MACS LS columns (Miltenyi Biotec). The remaining CD56 negative cells, which no longer contained NK cells, were then incubated with CD8 magnetic beads and positively selected using MACS LS columns. In these experiments, viability was determined by Trypan blue exclusion. CD8+ cells were cultured in 96-well flat-bottom plates at a density of 50,000 viable cells per $200 \mu \mathrm{l}$ lymphocyte culture media (10\% FBS, $1 \mathrm{mM}$ sodium pyruvate, $0.5 \mathrm{mM}$ 2-Mercaptoethanol, $1 \mathrm{mM}$ HEPES, $100 \mathrm{u} / \mathrm{ml}$ penicillin, $100 \mathrm{u} / \mathrm{ml}$ streptomycin, $0.292 \mathrm{mg} / \mathrm{ml} \mathrm{L}$-Glutamine in RPMI). Cells were stimulated with media alone, with plate-bound anti-CD3e $(5 \mu \mathrm{g} / \mathrm{ml})$ alone, or with antiCD3e plus each of the following TLR ligands: Pam3CSK4 $(1 \mu \mathrm{g} / \mathrm{ml})$, Heat-killed Listeria monocytogenes (HKLM; $10^{8}$ organisms/ml), Poly(I:C) $(10 \mu \mathrm{g} / \mathrm{ml})$, LPS E. coli $\mathrm{K} 12(1 \mu \mathrm{g} / \mathrm{ml})$, Flagellin Salmonella typhimurium $(1 \mu \mathrm{g} / \mathrm{ml})$, FSL-1 $(1 \mu \mathrm{g} / \mathrm{ml})$, Imiquimod $(1 \mu \mathrm{g} / \mathrm{ml})$, ssRNA $40(1 \mu \mathrm{g} / \mathrm{ml})$, or ODN 2006 , type B $(5 \mu \mathrm{M})$ (all agonists 
Table 2 Antibody staining panel

\begin{tabular}{|c|c|c|c|c|c|c|}
\hline Fluorochrome & 1 & 2 & 3 & 4 & 5 & 6 \\
\hline FITC & M IgG2a & TLR5 & CD45 & CD45 & CD45 & CD45 \\
\hline $\mathrm{PE}$ & IC:M IgG1 & IC:TLR3 & $M \lg G 1$ & TLR1 & IC:R IgG2a & IC:TLR9 \\
\hline Biotin (PE-Cy5) & & & $R \lg G 2 a$ & TLR6 & & \\
\hline PE-Cy7 & CD45 & CD45 & $M \lg G 1$ & TLR2 & M lgG2a & TLR4 \\
\hline APC & $M \lg G 2 a$ & CD56 & $M \lg G 2 \mathrm{a}$ & CD56 & M lgG2a & CD56 \\
\hline APC-Cy7 & $M \lg G 1$ & CD3 & $M \lg G 1$ & CD3 & $M \lg G 1$ & CD3 \\
\hline Pacific Blue & M lgG2a & CD8 & M lgG2a & $\mathrm{CD} 8$ & M lgG2a & CD8 \\
\hline Alexa Fluor 700 & $M \lg G 2 b$ & CD4 & $M \lg G 2 b$ & CD4 & $M \lg G 2 b$ & CD4 \\
\hline Aqua (AmCyan) & Live/Dead & Live/Dead & Live/Dead & Live/Dead & Live/Dead & Live/Dead \\
\hline
\end{tabular}

$M$, mouse; $R$, rat; IC, intra-cellular.

from InvivoGen, San Diego, CA) Cells were cultured at $37^{\circ} \mathrm{C}$ and $5 \% \mathrm{CO}_{2}$ for 48 hours, at which point supernatants were collected for analysis.

\section{Protein analysis of culture supernatants}

Cell culture supernatants were collected and stored at $-20^{\circ} \mathrm{C}$ until analyzed. Using the Luminex 200 system (Luminex Corporation, Austin, TX), protein levels for IFN- $\gamma$, TNF- $\alpha$, IL-13, perforin, granzyme A, granzyme B, soluble Fas ligand, (Biolegend, San Diego, CA) and CCL2, CCL3, CCL4, CCL5, CCL11, and CXCL9 (Invitrogen, Carlsbad, CA) were determined according to manufacturer's instructions.

\section{Statistics}

Statistical analysis was performed using SAS 9.1 statistical software (SAS Institute Inc., Cary, NC) and GraphPad Prism (GraphPad Software, Inc., La Jolla, CA). The Mann-Whitney t-test was used to compare TLR expression between subjects with COPD and subjects with normal pulmonary function. Kruskal-Wallis tests were used to look for significant differences between TLRligand treatment groups. Nonparametric (Spearman) correlation analysis was used to determine the correlation coefficient, $r_{S}$. Both linear and log transformed outcomes were considered. Multivariate regression examined the statistically significant relationships, adjusting for age and smoking exposure (pack years). A two-tailed $p$ value of $<0.05$ was considered to indicate significance.

\section{Results}

Identification of CD8+ T cell, CD4+ T cell, and NK cell subsets in human lung tissue

To determine whether lung $\mathrm{T}$ cells, NK cells and NK T cells express TLRs, we used 9-color flow cytometry to analyze expression of TLR1, TLR2/1, TLR2, TLR3, TLR4, TLR5, TLR6 and TLR9 on unpurified lung leukocytes from 28 subjects. We assessed both surface and intracellular expression of TLR3 and TLR9. We identified five different lymphocyte populations, including CD8+ $\mathrm{T}$ cells, CD4+ T cells, NK cells, CD8+ NKT cells, and CD4+ NKT cells. To identify these populations, we first gated on CD45+ low side scatter cells (Figure 1A) and then selected cells that were either CD3+ or CD3(Figure 1B). NK cells were defined as CD3- CD56+ CD4- CD8- cells (Figure 1C, E). CD8+ T cells were defined as being CD3+ CD8+ CD56-, while CD8+ NKT cells were CD3+ CD8+ CD56+ (Figure 1D, F). Similarly, CD4+ T cells were defined as CD3+ CD4+ CD56- cells and $\mathrm{CD} 4+\mathrm{NKT}$ cells were CD3+ CD4+ CD56+ (Figure 1D, G). We saw no difference in the frequency of any of the cell types when comparing healthy smokers to COPD subjects (data not shown). On average, the frequency as a percent of CD45+ cells was $7.6 \%$ for CD8+ $\mathrm{T}$ cells, $8.8 \%$ for CD4+ T cells, $5.0 \%$ for NK cells, $1.3 \%$ for CD8+ NKT cells, and $0.6 \%$ for CD4+ NKT cells.

\section{Increased percentage of lung CD8+ T cells expressing TLRs in COPD and emphysema}

After gating on our cell population of interest, we used a $5 \%$ probability contour plot to select positive events, as distinguished from negative events by the isotype control. With this strategy, we were able to determine the percentage of CD8+ T cells, CD4+ T cells, NK cells and NK T cells that expressed a given TLR. Analysis of the TLR expression on 28 subjects ( $n=10$ subjects with normal pulmonary function, $n=18$ subjects with COPD) revealed that the percentage of lung $\mathrm{CD} 8+\mathrm{T}$ cells expressing TLR1, TLR2, TLR4, TLR6, and TLR2/1 was significantly increased in subjects with COPD compared to the subjects without COPD (Figure 2 and Figure 3, left panel). Lung CD8+ T cells also expressed TLR3, TLR5, and TLR9 ( $10 \%$ of cells), but the percentage of positive cells did not show a significant difference between subject groups (data not shown). Interestingly, in contrast to the CD8+ T cell findings, although CD4+ T cells, CD56+ NK cells and NKT cells were analyzed simultaneously in the same sample, only the expression of TLR2/1 on the lung CD4+ T cells and the expression of 


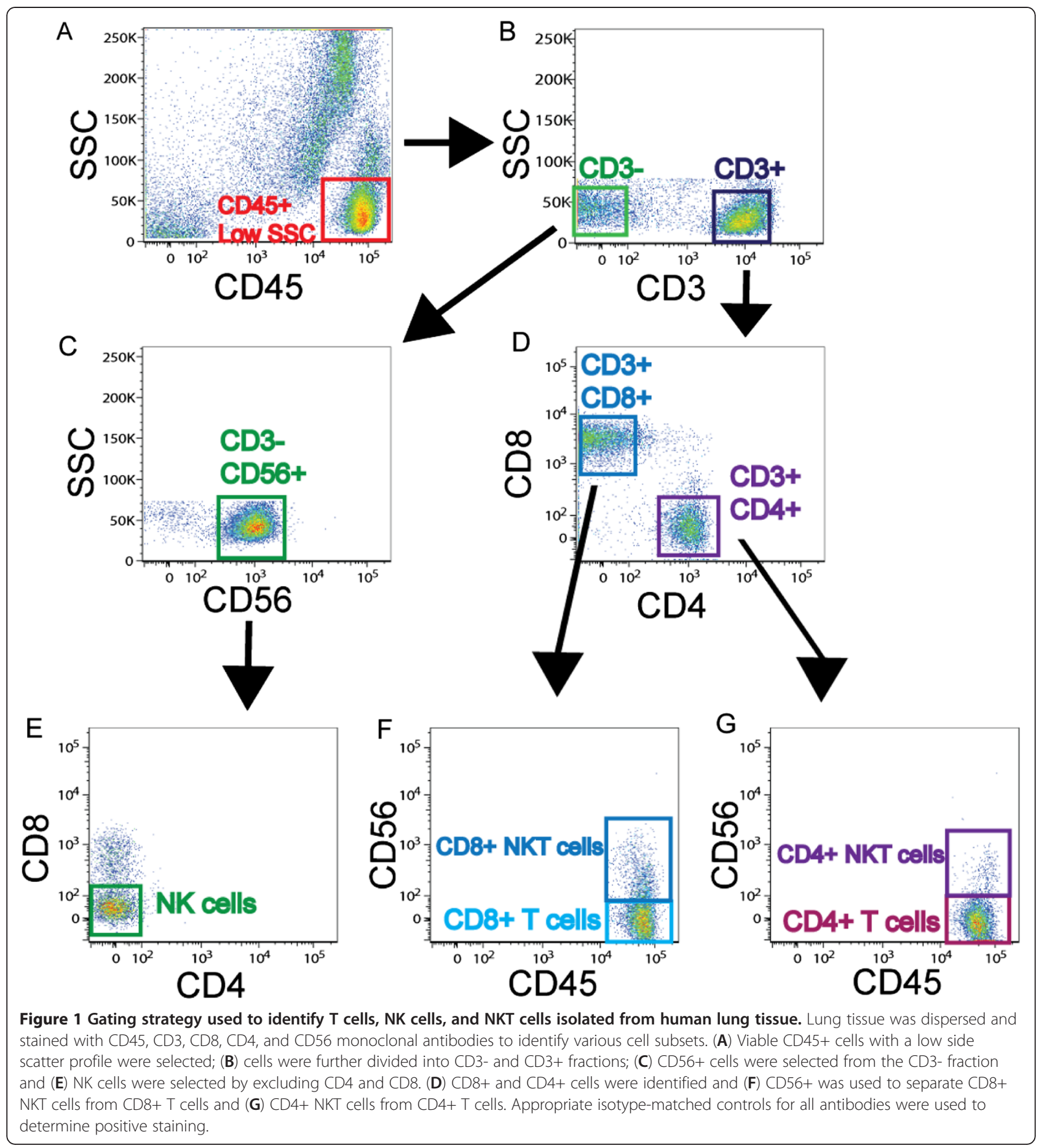

TLR2 on the CD8+ NKT cells was significantly increased in the subjects with COPD (Figure 3, middle and right panels; data not shown for NKT cells). As shown in the subject demographics (Table 1), healthy smokers and subjects with COPD showed significant differences in their clinical indication for surgery and their inhaled corticosteroid (ICS) use. To ensure that the presence of lung cancer or ICS use were not responsible for the difference in TLR expression between healthy smokers and COPD subjects, we analyzed these parameters in the COPD cohort. We saw no difference in TLR expression when the subjects with COPD were stratified by surgical indication or ICS use, suggesting that these variables are not contributing to the difference in TLR expression. 


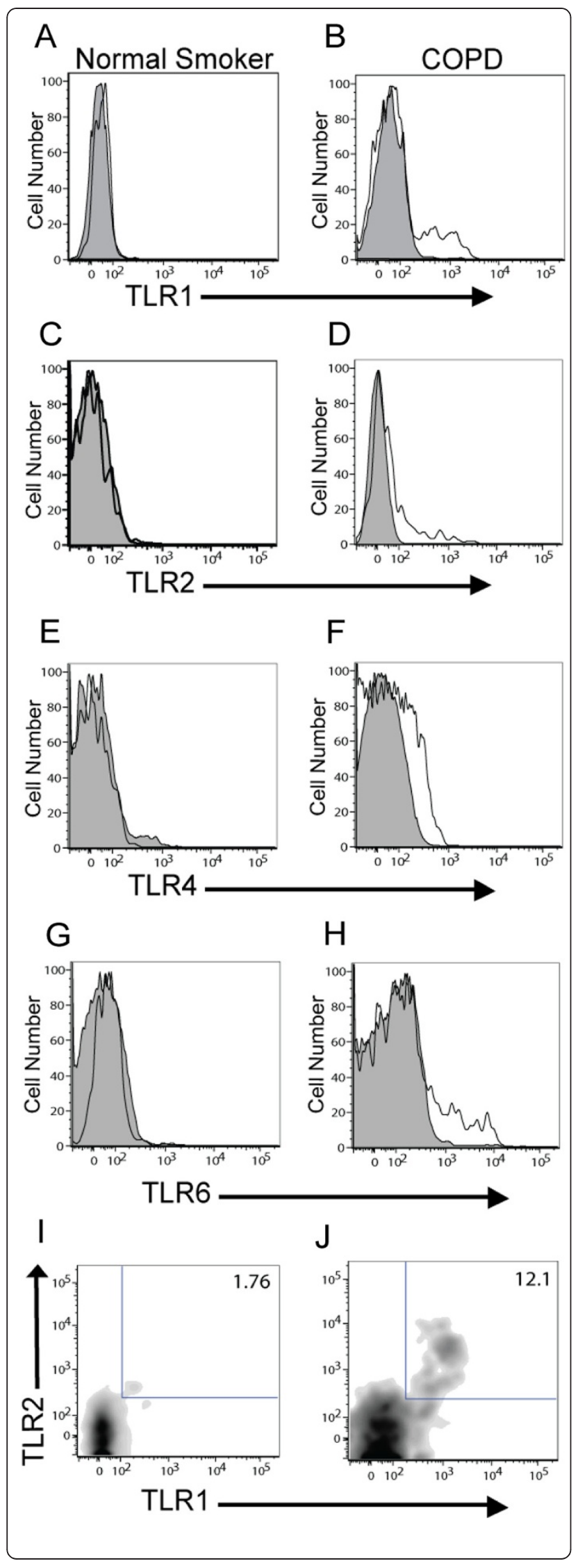

Figure 2 Representative histograms demonstrating an increase in TLR expression on lung CD8+ T cells in COPD. CD8+ CD56cells from human lung tissue were identified as described in the legend to Figure 1 and examined for TLR expression. Left panels are representative histograms $(\mathbf{A}, \mathbf{C}, \mathbf{E}, \mathbf{G})$ or density plot (I) from smokers without COPD and right panels are representative histograms $(\mathbf{B}, \mathbf{D}, \mathbf{F}, \mathbf{H})$ or density plot (J) from subjects with COPD. Expression of (A, B) TLR1, (C, D) TLR2, (E, F) TLR4, (G, H) TLR6, and (I, J) TLR2/1 are shown. Shaded profile, isotype staining; open profiles, antibody-specific staining.

Expression of TLRs by lung CD8+ T cells also showed correlation with percent emphysema, calculated from non-contrast computed tomography (CT) scans that were available for 13 patients. The percentage of lung CD8+ T cells expressing TLR5 and TLR2/1 increased with worsening emphysema (Table 3 and Figure 4A,B). Similarly, NK cells expressing TLR5, TLR6, and TLR2/1 also correlated with worsening emphysema as determined by CT quantification (Table 3 and Figure 4C-E). The magnitude and direction of these correlations remained similar, although significance was attenuated after adjustment for age and smoking status as independent variables. The expression of TLRs on lung CD4+ T cells and NKT cells did not correlate with percent emphysema, implying that the regulation of TLRs within the lung environment in a given patient differs between lymphocyte subsets.

\section{TLR stimulation of lung CD8+ T cells results in increased cytokine production}

Based on our previous finding that human lung CD8+ T cell transcripts for IFN- $\gamma$, perforin, and granzyme B are increased in later stages of COPD [6,7], we hypothesized that augmented production of these molecules might result from TLR-mediated response to danger signals in the lung environment. To test this hypothesis, CD8+ CD56- T cells isolated from lung tissue of COPD subjects were stimulated in vitro with plate-bound anti-CD3e, plus each of the following TLR ligands: Pam3CSK4, heat-killed Listeria monocytogenes (HKLM), Poly(I:C), LPS, Flagellin, FSL-1, Imiquimod, ssRNA40, ODN 2006. Cells were stimulated for 48 hours and then supernatants were collected for protein analysis. Multiplex beads were used to measure IFN- $\gamma$, TNF- $\alpha$, IL-13, perforin, granzyme A, granzyme B, and soluble fas ligand. Only Pam3CSK4, the ligand for TLR2/1, induced significant increases in IFN- $\gamma$ and TNF- $\alpha$ (Figure 5A,B). Due to variability in baseline response between individual subjects, we first analyzed results expressed as the fold-change compared to the control stimulated with anti-CD3e alone $(n=7)$. None of the other agonists induced significant increases in expression (HKLM, LPS, and Flagellin shown in Figure 5A-C; results not shown for Poly(I:C), FSL-1, Imiquimod, ssRNA40, or ODN 2006). Furthermore, the effect of TLR2/1 


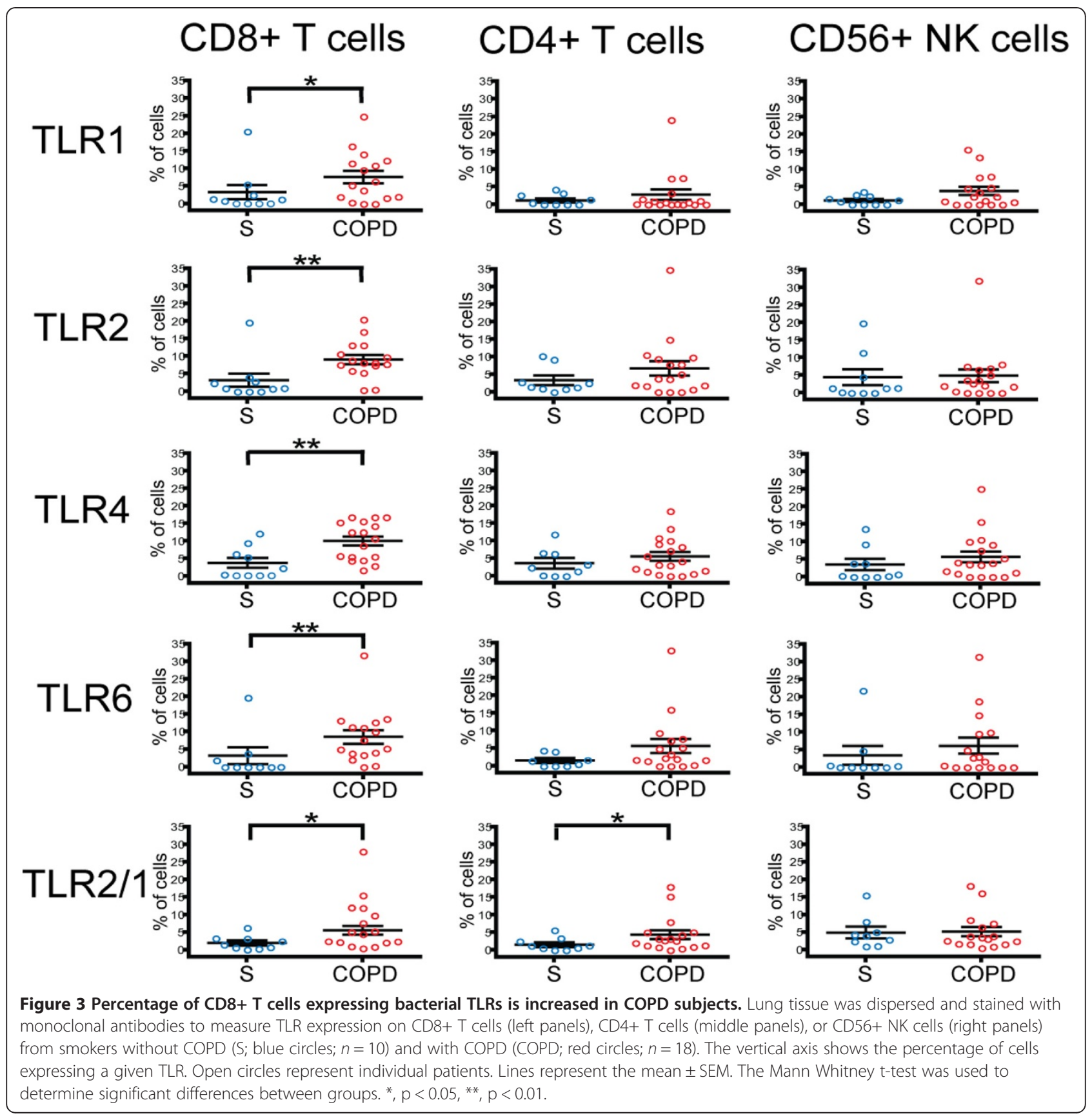

stimulation appeared limited to Tc1 cytokine expression, as there was no increase in either IL-13 (Figure 5C) or cytotoxic molecules (data not shown). Stimulation of the lung CD8+ T cells with the TLR2/1 agonist Pam3CSK4 also resulted in a 3-fold increase in the chemokine CCL3 (Figure 5D). No significant differences were observed in the other chemokines measured (CCL2, CCL4, CCL5, CCL11 and CXCL9). No increase in protein levels over the unstimulated control was seen when lung CD8+ T cells were cultured with TLR ligands in the absence of anti-CD3 $\varepsilon$ (data not shown), suggesting that TLRs function solely as co-stimulatory molecules, as has been reported, and do not independently activate lung $\mathrm{T}$ cells. Of the seven COPD subjects used in these in vitro experiments, three had lung resections and four were explants; six subjects were taking ICS. Thus, although surgical indication did not appear to play a role in the increase production of IFN- $\gamma$, TNF- $\alpha$, and CCL3, we are unable to rule out a possible effect of the ICS. The absolute values for IFN- $\gamma$, TNF- $\alpha$, IL-13, and CCL3 are also shown (Figure 5E-H). Following stimulation with anti-CD3e and Pam3CSK4, IFN- $\gamma$ and CCL3 averaged 4,000 pg/mL, which was 10-fold higher 
Table 3 Summary of correlation between percentage of lung subsets expressing TLRs and emphysema score

\begin{tabular}{llll}
\hline Subset & TLR & $r_{s}$ Value & $p$ Value \\
\hline CD8+ & TLR1 & 0.54 & 0.09 \\
T Cells & TLR2 & 0.59 & 0.06 \\
& TLR4 & 0.37 & 0.23 \\
& TLR5 & 0.62 & 0.03 \\
& TLR6 & 0.59 & 0.05 \\
CD4+ & TLR2/1 & 0.70 & 0.01 \\
T cells & TLR1 & 0.09 & 0.77 \\
& TLR2 & 0.52 & 0.09 \\
& TLR4 & 0.11 & 0.72 \\
& TLR5 & 0.30 & 0.32 \\
CD56+ & TLR6 & 0.21 & 0.50 \\
NK cells & TLR2/1 & 0.27 & 0.39 \\
& TLR1 & 0.51 & 0.09 \\
& TLR2 & 0.47 & 0.12 \\
& TLR4 & 0.35 & 0.24 \\
& TLR5 & 0.64 & 0.02 \\
& TLR6 & 0.60 & 0.04 \\
& TLR2/1 & 0.63 & 0.03 \\
\hline
\end{tabular}

than TNF- $\alpha$ and 100-fold greater than IL-13 levels. Although there is an increase in the average of IFN- $\gamma$, TNF- $\alpha$, and CCL3 following stimulation with Pam3CSK4, the data did not achieve statistical significance, due to the marked variation in baseline response between individual subjects.

Finally, to determine whether the increase in IFN- $\gamma$, TNF- $\alpha$ and CCL3 following TLR2/1 stimulation was specific to lung CD8+ T cells from COPD subjects, we also exposed lung CD8+ CD56- cells from control subjects to Pam3CSK4 (Figure 6A-D). Lung CD8+ $\mathrm{T}$ cells from COPD subjects $(n=7)$ produced significantly more IFN- $\gamma$ and TNF- $\alpha$ than CD8+ T cells from control subjects $(n=5)$. No difference was seen in the production of IL-13 or CCL3. These results suggest that in COPD, the increased number of lung CD8+ T cells expressing TLR2/1 are able to contribute to an augmented inflammatory response following TLR2/1 stimulation. The absolute values for IFN-TNF- $\alpha$, IL-13, and CCL3 are shown (Figure 6E-H).

\section{Discussion}

The principal results of this analysis of TLR molecules on human lung T cells, NK cells and NKT cells demonstrate for the first time several observations relevant to COPD pathogenesis. First, expression of multiple TLRs on lung CD8+ $\mathrm{T}$ cells (but not on simultaneously analyzed lung CD4+ T cells, NK cells or NKT cells) was increased in COPD patients relative to smokers with preserved lung function. Second, TLR2/1 molecules expressed by lung CD8+ $\mathrm{T}$ cells were functional, as shown by the markedly enhanced production of cytokines linked to lung inflammation and COPD progression following co-stimulation by the TLR2/1 agonist in vitro. Third, expression by lung CD8+ T cells of TLR $2 / 1$ and TLR5 correlated significantly with quantitative emphysema scores in univariate analysis. Collectively, these findings strengthen the evidence linking lung $\mathrm{CD} 8+\mathrm{T}$ cells to smoking-induced lung destruction in susceptible cigarette smokers.

The finding that an increased percentage of lung CD8+ $\mathrm{T}$ cells express TLR1, TLR2, TLR2/1, TLR4 and TLR6 in COPD subjects extends to human lung parenchyma and to a specific disease state the results of previous studies of peripheral blood from healthy humans $[16,19,20,26,27]$. Although many TLRs have multiple ligands, it is noteworthy that increased expression was seen in the cell surface receptors most strongly associated with bacterial recognition (TLR1, TLR2, TLR2/1, TLR4 and TLR6), and not in the endosomal receptors TLR3 or TLR9, which recognize viruses and endogenous danger signals [28]. Furthermore, the very strong correlation between TLR5 or TLR2/1 and emphysema severity suggests that TLRs on lung CD8+ T cells may be specifically contributing to the pathogenesis of emphysema and highlights the importance of defining specific COPD phenotypes in selecting patients for personalized therapies [29]. Additional experiments will be needed to determine whether the co-stimulatory effect of TLR ligation is additive or synergistic when multiple TLRs are stimulated simultaneously, as would plausibly occur during exacerbations of COPD. Neither the presence of lung cancer nor recent infections appeared to contribute to the difference in TLR expression that we observed between healthy subjects and COPD subjects. Little is known about the effect of glucocorticoids on TLRs, but it has been shown that dexamethasone, in combination with IFN- $\gamma$ or TNF- $\alpha$, was able to synergistically enhance TLR2 expression on respiratory epithelial cells [30]; however in a separate study, dexamethasone was shown to downregulate TLR4 expression in an airway epithelial cell line [31]. The effect of steroids on TLRs has not been investigated in $\mathrm{T}$ cells. In our study, we saw no difference in TLR expression when ICS use was evaluated.

Although we also detected expression of multiple TLRs on lung CD4+ T cells, the near complete lack of their increased expression on this cell type in COPD, relative to age-matched smokers with preserved spirometry, implies either that the regulation or significance of TLR expression on CD4+ lung T cells, or the role of that subset itself, differs in COPD from that of lung CD8+ T cells. It is interesting that on the CD56+ NK cells, TLR5, 
Figure 4 Expression of TLR5 and TLR2/1 on lung CD8+ T cells and NK cells increases with worsening emphysema. Lung tissue was stained with monoclonal antibodies to measure TLR expression on T cells, NK cells, and NKT cells. Expression (vertical axis) of (A) TLR5 on CD8+ T cells, (B) TLR2/1 on CD8+ T cells, (C) TLR5 on NK cells, (D) TLR6 on NK cells, (E) TLR2/1 on NK cells, stratified by percent emphysema ( $-950 \mathrm{HU}$ threshold) (horizontal axis). Open circles represent individual patients, $n=13$. Spearman nonparametric analysis was used to calculate the $r_{s}$ value.

TLR6, and TLR2/1 only showed a correlation with emphysema severity but showed no difference between COPD subjects and controls. These finding are compatible with the suggestion by Borchers and colleagues [32] that NK cells are particularly crucial in emphysema pathogenesis. Collectively, our findings support previous studies [33-37] on the importance of adaptive immune responses in emphysematous lung destruction. Whether TLR expression is restricted to specific CD8+ $T$ cell clones, especially those with autoreactivity, will require further study, although the rather low fraction of total lung CD8+ expressing TLRs in the current study would be compatible with that possibility.

Lung CD8+ T cells in COPD appear especially sensitive to stimulation through the TLR2/1 heterodimer, as shown by the results of co-stimulation by the specific agonist Pam3CSK4. Our findings extend to the human system the finding that murine ovalbumin-specific OT-1 cytotoxic $\mathrm{T}$ lymphocytes responded to TLR2/1 stimulation with increased levels of IFN- $\gamma$ at both the RNA and protein levels [38]. TLR2 is known to recognize the most diverse repertoire of microbe-associated patterns, in part through its unique ability to heterodimerize with either TLR1 or TLR6. TLR2/1 heterodimers are primarily responsible for recognizing triacylated lipoproteins, such as the outer membrane proteins of nontypeable Haemophilus influenzae (NTHI) [39]. This organism is one of the predominant bacterial pathogens associated with airway infection in COPD, both in stable disease and as an important infectious trigger of exacerbations [40,41]. Although the presence of TLR2/1 on lung CD8+ $\mathrm{T}$ cells might play a role in host defense in early COPD, repeated cycles of infection could swing the balance from host defense to inappropriate activation and subsequent tissue damage. Importantly, NTHI can be an intracellular pathogen of respiratory epithelial cells and macrophages $[42,43]$, suggesting the possibility for presentation both of NTHI-derived antigens in the context of class I MHC molecules and of their lipoproteins to TLR2/1 on lung CD8+ T cells. A recent study by King and colleagues used live NTHI to stimulate T cells from the lungs of COPD subjects and control subjects [44]. They found that both $\mathrm{CD} 4+$ and $\mathrm{CD} 8+\mathrm{T}$ cells from COPD subjects produced significantly higher levels of TNF- $\alpha$, 


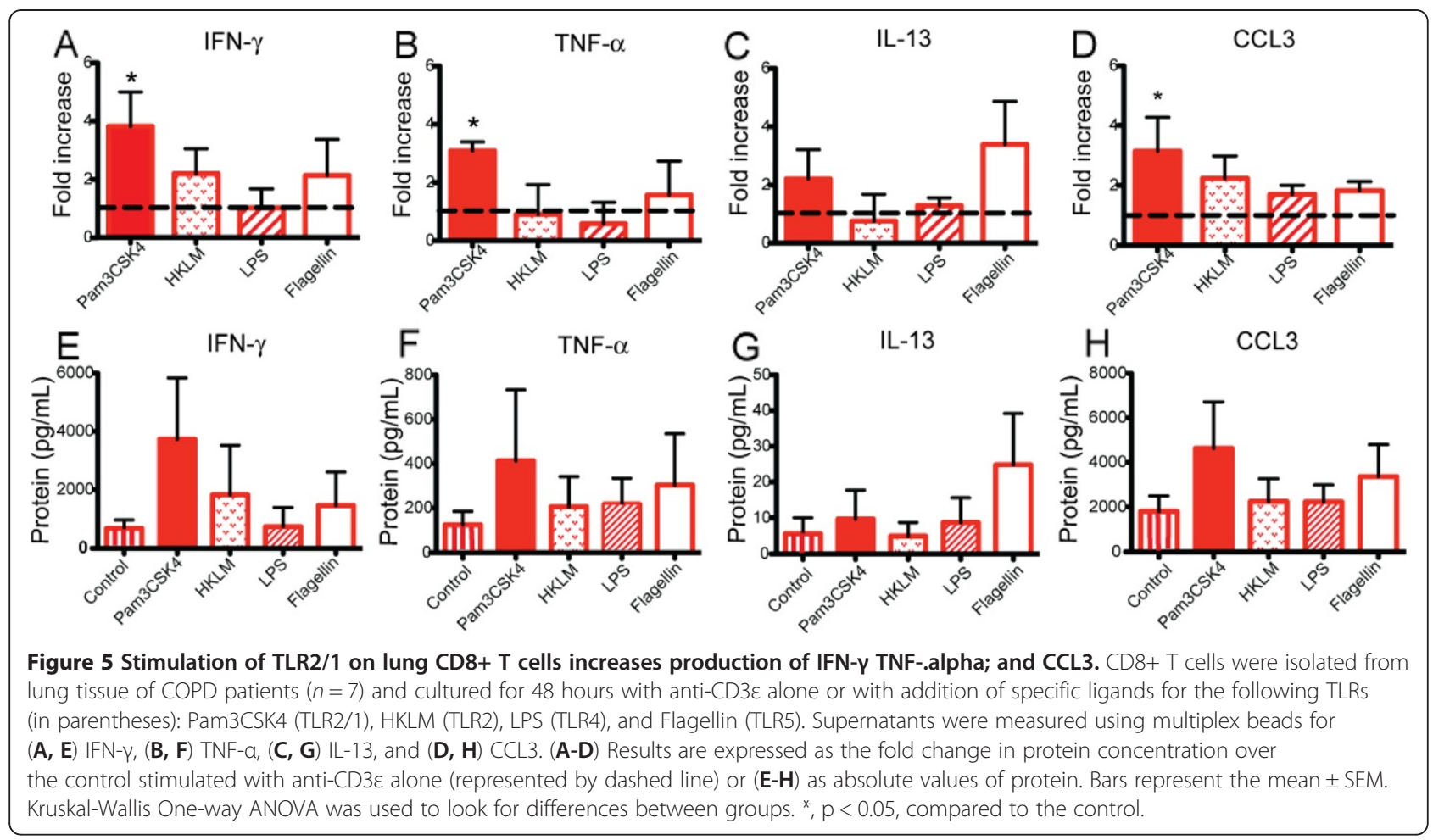

IL-17, and IL-13. Additional experiments will be needed to confirm whether TLRs have a role in this response.

The range of effector molecules significantly increased by co-stimulation via TLR2/1 (IFN- $\gamma$, TNF- $\alpha$ and the chemokine CCL3) is also intriguing. Transgenic overexpression of IFN- $\gamma$ in the lungs induces production of matrix metalloproteinases by macrophages and development of emphysema in a murine model [45], Similarly, a central role for TNF- $\alpha$ in smoking-induced emphysema development is well-supported by data from murine models [46-48], likely reflecting in part the ability of TNF- $\alpha$ to activate endothelial cells to increase

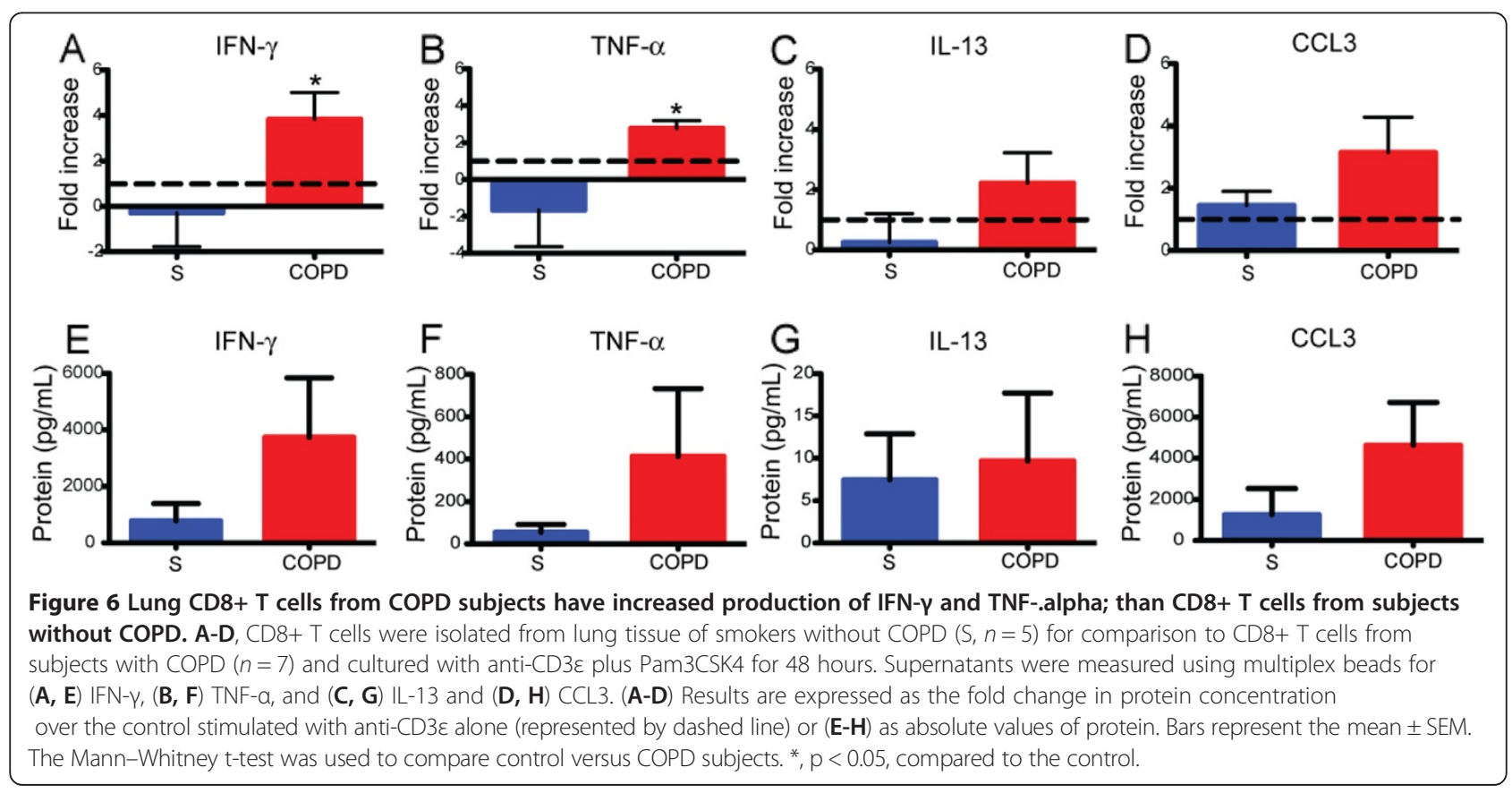


recruitment of inflammatory cells. CCL3 (previously known as MIP-1 $\alpha$ ) is a ligand for the chemokine receptors CCR1 and CCR5, and we previously showed that expression of CCR5 by lung CD8+ T cells increases with spirometrically-defined COPD severity [6]. Hence, stimulation via TLR2/1 and possibly other TLRs could generate a positive feed-back loop via CCR5 inducing the accumulation of lung CD8+ T cells seen in COPD.

Collectively, the current results agree with our previous finding that lung CD8+ $\mathrm{T}$ cells in COPD have a Tc1 phenotype and lack Tc2 cytokine secretion, even following TCR-dependent or TCR-independent stimulation [7]. The practical importance of the small, statistically insignificant increases in IL-13 protein production following stimulation with flagellin is questionable, because its concentration was so much lower than that of IFN- $\gamma$ (100-fold less) and TNF- $\alpha$ (10-fold less). Because we had previously shown that perforin and granzyme $\mathrm{B}$ transcripts from lung CD8 $+\mathrm{T}$ cells were increased in severe COPD [7], we were surprised to see that TLR-stimulation did not increase production of perforin or granzyme B. It is possible that perforin and granzyme were increased in the intracellular granules of the CD8+ T cells but release of these molecules into the supernatant requires CD8+ degranulation. If the CD8+ T cells did not degranulate, then any increases in perforin or granzyme B would only be detectable with intracellular flow cytometry, which we did not perform in these particular experiments.

Our results differ in several respects from a previous study by Nadigel and colleagues, which found that both TLR4 and TLR9 were increased on lung CD8+ T cells from COPD patients [24], relative to healthy control subjects with normal spirometry who included two exsmokers and three never-smokers. Although our study confirmed the finding of increased TLR4 expression, we did not see an increase in TLR9 expression in COPD relative to our reference population, who were entirely active smokers or ex-smokers. Furthermore, in our analysis, the percentage of lung CD8+ T cells expressing TLR4 only modestly increased in COPD, whereas they saw an increase from $20 \%$ in the control lung tissue to 90\% in the COPD lung tissue [24]. These differences can likely be attributed to the tissue sample and techniques that were used. Nadigel et al. used immunofluorescence microscopy to analyze TLR expression of CD8+ T cells in endobronchial biopsies (i.e., relatively large airways) [24]. We used flow cytometry, which permits very objective quantification of specific staining relative to isotype control antibody, and we analyzed dispersed tissue from the distal lung compartment. CD8+ T cells are present in the central and peripheral airways and lung parenchyma in COPD, but the number of CD8+ T cells in the distal airways negatively correlates with airflow obstruction in patients with COPD [49], suggesting that this is a key location in COPD pathogenesis [3].

It is well documented that TLRs are expressed prominently on antigen-presenting cells, such as dendritic cells, and therefore play an important, if indirect, role in the initiation of adaptive $\mathrm{T}$ cell responses. TLR expression by macrophages and $\mathrm{B}$ cells can also contribute to production of antibodies and of chemokines. It is less clear whether the direct signaling of TLRs on T cells has the same physiological importance. On the one hand, the requirement for stimulation via the TCR, shown in this study and others, implies that TLRs are serving a primarily co-stimulatory role in $\mathrm{CD} 8+\mathrm{T}$ cells. Indeed, numerous studies have shown that a number of TLR ligands can provide co-stimulatory signals to $\mathrm{T}$ cells, even in the absence of CD28 engagement [16-20]. Additional studies have suggested that TLR signaling through myeloid differentiation protein 88 (MyD88) may increase the clonal expansion and survival of activated $\mathrm{T}$ cells $[50,51]$. Conversely, the other lung cell types that express TLRs (dendritic cells, macrophages, B cells and epithelial cells) cannot produce IFN- $\gamma$, a unique cytokine that has both protective and potentially damaging properties. Thus, the current findings collectively suggest that lung CD8+ $\mathrm{T}$ cells use TLRs to sense and respond to microenvironmental conditions and to receive additional signals at the site of injury.

\section{Conclusions}

In summary, human lung CD8+ $\mathrm{T}$ cells seem able to respond to danger signals in their environment, especially bacterial colonization of the lower respiratory tract, by up-regulating their potential to produce inflammatory mediators and cytotoxic molecules when stimulated via their cognate antigen receptors. Together with progressive upregulation of TLRs on lung CD8+ T cells as COPD worsens, this mechanism could contribute to lung destruction during respiratory infections.

\section{Abbreviations}

CT: Computed tomography; COPD: Chronic obstructive pulmonary disease; FEV1: Forced expiratory volume in one second; FVC: Forced vital capacity; GOLD: Global Initiative for chronic Obstructive Lung Disease; HKLM: Heatkilled Listeria monocytogenes; ICS: Inhaled corticosteroids; NK: Natural killer; NTHI: Nontypeable Haemophilus influenzae; S: Smoker without COPD; TLR: Toll-like receptor.

\section{Competing interests}

GRW, ALM, SWC, DAA, CAM, and LM have no competing interests to declare. F.J.M. has been a member of advisory boards for Actellion, Ikaria, Merck,

Pearl, Pfizer, Jannsen, GlaxoSmithKline, Schering Plough, Novartis, Nycomed, Genzyme, Forest/Almirall, Medlmmune, AstraZeneca, Potomac, Bayer, Elan,

Talecris, and Roche. He has been on the speaker's bureau for Forest/Almirall, Nycomed, Bayer, Boehringer Ingelheim, GlaxoSmithKline, France Foundation, MedEd, NACE, and AstraZeneca. He has also been a member of steering committees for studies supported by Altana/Nycomed, GlaxoSmithKline, Gilead, Actelion, Johnson/Johnson, Mpex, UCB, and the National Institutes of Health. He has been an investigator in trials supported by Boehringer Ingelheim and Actelion. M.K.H. has been a consultant for Boehringer 
Ingelheim, Pfizer, GlaxoSmithKline, Medlmmune, Novartis, Grifols Therapeutics, and United Biosource Corporation. CMF and JLC are supported by research grants as outlined in the Endnotes.

\section{Authors' contributions}

CMF: Designed and performed experiments, analyzed data, produced graphs and tables, wrote manuscript; FJM: performed analyses and assisted in procuring human specimens, reviewed manuscript; $\mathrm{MKH}$ : performed analyses, reviewed manuscript; GRW: obtained emphysema scores from CT scans, reviewed manuscript; ALM: assisted in planning of experiments, reviewed manuscript; SWC: oversaw collection of surgical lung specimens, reviewed manuscript: DAA: aided in collection of surgical lung specimens, reviewed manuscript; CAM: consented surgical subjects and maintained records; LM: consented surgical subjects, maintained records, ensured compliance with IRB; JLC: secured research funding, oversaw study design, analyzed data and assisted in generating the final manuscript. All authors read and approved the final manuscript.

\section{Acknowledgments}

The authors thank Dr. Catherine Spino and Glen Feak for database support: Liujian Zhao for assistance in tissue processing; Christi Getty and Dr. Deborah Thompson for support in patient recruitment; Theresa Ames, Timothy Polak and Joanne Sonstein for laboratory assistance; and Mary Freer, Joyce O'Brien, Sara Whisenant and Rebecca Weeks for administrative support. Sources of support: Merit Review Award (CMF) and a Research Enhancement Award Program from the Biomedical Laboratory Research \& Development Service, Department of Veterans Affairs; R01 HL082480 (JLC, FJM), K23 HL093351, and K24 HL04212 from the USPHS. These investigations were also supported in part by the Tissue Procurement Core of the University of Michigan Comprehensive Cancer Center, Grant P30 CA46952; and by the Lung Tissue Research Consortium (Clinical Centers), grant N01 HR046162. This study was registered with ClinicalTrials.gov as NCT00281229. These data were presented in part at the International Scientific Conference of the American Thoracic Society, May 17, 2010 in New Orleans, LA, and have been published in abstract form Am J Respir Crit Care Med 2010; 181: A3866.

\section{Author details}

${ }^{1}$ Research Service, Department of Veterans Affairs Healthcare System, Ann Arbor, Ml 48105, USA. Division of Pulmonary \& Critical Care Medicine, Department of Internal Medicine, University of Michigan Health System, Ann Arbor, MI 48109, USA. ${ }^{3}$ Division of Pulmonary and Critical Care Medicine, Department of Medicine, Brigham \& Women's Hospital and Harvard University, Boston, MA 02115, USA. ${ }^{4}$ Graduate Program in Immunology, University of Michigan, Ann Arbor, MI 48109, USA. ${ }^{5}$ Pathology \& Laboratory Medicine Service, VA Ann Arbor Healthcare System, Ann Arbor, Ml 48105, USA. ${ }^{6}$ Medical Service, VA Ann Arbor Healthcare System, Ann Arbor, MI 48105, USA. ${ }^{7}$ Department of Pathology, University of Michigan Health System, Ann Arbor, MI 48109, USA

Received: 2 November 2012 Accepted: 29 January 2013 Published: 1 February 2013

\section{References}

1. Minino JX AM, Kochanek KD: Deaths: Preliminary Data for 2008. Nat/ Vital Stat Rep 2010, 59:1-72

2. Barnes PJ, Celli BR: Systemic manifestations and comorbidities of COPD. Eur Respir J 2009, 33:1165-1185.

3. Hogg JC, Chu F, Utokaparch S, Woods R, Elliott WM, Buzatu L, Cherniack RM, Rogers RM, Sciurba FC, Coxson HO, Pare PD: The nature of small-airway obstruction in chronic obstructive pulmonary disease. N Engl J Med 2004, 350:2645-2653.

4. Saetta M, Baraldo S, Corbino L, Turato G, Braccioni F, Rea F, Cavallesco G, Tropeano G, Mapp CE, Maestrelli P, et al: CD8 + ve cells in the lungs of smokers with chronic obstructive pulmonary disease. Am J Respir Crit Care Med 1999, 160:711-717.

5. O'Shaughnessy TC, Ansari TW, Barnes NC, Jeffery PK: Inflammation in bronchial biopsies of subjects with chronic bronchitis: inverse relationship of CD8+ T lymphocytes with FEV1. Am J Respir Crit Care Med 1997, 155:852-857.

6. Freeman CM, Curtis JL, Chensue SW: CC chemokine receptor 5 and CXC chemokine receptor 6 expression by lung CD8+ cells correlates with chronic obstructive pulmonary disease severity. Am J Pathol 2007, 171:767-776.
7. Freeman CM, Han MK, Martinez FJ, Murray S, Liu LX, Chensue SW, Polak TJ, Sonstein J, Todt JC, Ames TM, et al: Cytotoxic potential of lung CD8(+) T cells increases with chronic obstructive pulmonary disease severity and with in vitro stimulation by IL-18 or IL-15. J Immunol 2010, 184:6504-6513.

8. Maeno T, Houghton AM, Quintero PA, Grumelli S, Owen CA, Shapiro SD: CD8+ T Cells are required for inflammation and destruction in cigarette smoke-induced emphysema in mice. J Immunol 2007, 178:8090-8096.

9. Borchers MT, Wesselkamper SC, Harris NL, Deshmukh H, Beckman E, Vitucc M, Tichelaar JW, Leikauf GD: CD8+ T cells contribute to macrophage accumulation and airspace enlargement following repeated irritant exposure. Exp Mol Pathol 2007, 83:301-310.

10. O'Donnell R, Breen D, Wilson S, Djukanovic R: Inflammatory cells in the airways in COPD. Thorax 2006, 61:448-454.

11. Vijayanand P, Seumois G, Pickard C, Powell RM, Angco G, Sammut D, Gadola SD, Friedmann PS, Djukanovic R: Invariant natural killer T cells in asthma and chronic obstructive pulmonary disease. N Engl J Med 2007, 356:1410-1422.

12. Urbanowicz RA, Lamb JR, Todd I, Corne JM, Fairclough LC: Altered effector function of peripheral cytotoxic cells in COPD. Resp Res 2009, 10:53.

13. Chi SY, Ban HJ, Kwon YS, Oh IJ, Kim KS, Kim YI, Kim YC, Lim SC: Invariant natural killer T cells in chronic obstructive pulmonary disease. Respirology 2012, 17:486-492.

14. Urbanowicz RA, Lamb JR, Todd I, Corne JM, Fairclough LC: Enhanced effector function of cytotoxic cells in the induced sputum of COPD patients. Resp Res 2010, 11:76.

15. Hodge G, Mukaro V, Holmes M, Reynolds PN, Hodge S: Enhanced cytotoxic function of NK and NKT-like cells associated with decreased CD94 (Kp43) in the COPD airway. Respirology 2012, 18:369-376.

16. Caron G, Duluc D, Fremaux I, Jeannin P, David C, Gascan H, Delneste Y: Direct stimulation of human T cells via TLR5 and TLR7/8: flagellin and R-848 up-regulate proliferation and IFN-gamma production by memory CD4+ T cells. J Immunol 2005, 175:1551-1557

17. Cottalorda A, Verschelde C, Marcais A, Tomkowiak M, Musette P, Uematsu S, Akira S, Marvel J, Bonnefoy-Berard N: TLR2 engagement on CD8 T cells lowers the threshold for optimal antigen-induced T cell activation. Eur J Immunol 2006, 36:1684-1693.

18. Gelman AE, Zhang J, Choi Y, Turka LA: Toll-like receptor ligands directly promote activated CD4+ T cell survival. J Immunol 2004, 172:6065-6073.

19. Tabiasco J, Devevre E, Rufer N, Salaun B, Cerottini JC, Speiser D, Romero P: Human effector CD8+ T lymphocytes express TLR3 as a functional coreceptor. J Immunol 2006, 177:8708-8713.

20. Komai-Koma M, Gilchrist DS, Xu D: Direct recognition of LPS by human but not murine CD8+ T cells via TLR4 complex. Eur J Immunol 2009, 39:1564-1572.

21. Hervas-Stubbs S, Olivier A, Boisgerault F, Thieblemont N, Leclerc C: TLR3 ligand stimulates fully functional memory CD8+ T cells in the absence of CD4+ T-cell help. Blood 2007, 109:5318-5326.

22. Qiu F, Maniar A, Diaz MQ, Chapoval Al, Medvedev AE: Activation of cytokine-producing and antitumor activities of natural killer cells and macrophages by engagement of Toll-like and NOD-like receptors. Innate Immun 2011, 17:375-387.

23. Motz GT, Eppert BL, Wortham BW, Amos-Kroohs RM, Flury JL, Wesselkamper SC, Borchers MT: Chronic cigarette smoke exposure primes NK cell activation in a mouse model of chronic obstructive pulmonary disease. $\mathrm{J}$ Immunol 2010, 184:4460-4469.

24. Nadigel J, Prefontaine D, Baglole CJ, Maltais F, Bourbeau J, Eidelman DH, Hamid Q: Cigarette smoke increases TLR4 and TLR9 expression and induces cytokine production from CD8(+) T cells in chronic obstructive pulmonary disease. Resp Res 2011, 12:149.

25. Rabe KF, Hurd S, Anzueto A, Barnes PJ, Buist SA, Calverley P, Fukuchi Y, Jenkins C, Rodriguez-Roisin R, van Weel C, Zielinski J: Global strategy for the diagnosis, management, and prevention of chronic obstructive pulmonary disease: GOLD executive summary. Am J Respir Crit Care Med 2007, 176:532-555.

26. Hornung V, Rothenfusser S, Britsch S, Krug A, Jahrsdorfer B, Giese T, Endres S. Hartmann G: Quantitative expression of toll-like receptor 1-10 mRNA in cellular subsets of human peripheral blood mononuclear cells and sensitivity to CpG oligodeoxynucleotides. J Immunol 2002, 168:4531-4537.

27. Zarember KA, Godowski PJ: Tissue expression of human Toll-like receptors and differential regulation of Toll-like receptor mRNAs in leukocytes in response to microbes, their products, and cytokines. J Immunol 2002, 168:554-561. 
28. Kariko $\mathrm{K}, \mathrm{Ni} \mathrm{H}$, Capodici J, Lamphier M, Weissman D: mRNA is an endogenous ligand for Toll-like receptor 3. J Biol Chem 2004, 279:12542-12550.

29. Han MK, Agusti A, Calverley PM, Celli BR, Criner G, Curtis JL, Fabbri LM, Goldin JG, Jones PW, Macnee W, et al: Chronic obstructive pulmonary disease phenotypes: the future of COPD. Am J Respir Crit Care Med 2010, 182:598-604.

30. Homma T, Kato A, Hashimoto N, Batchelor J, Yoshikawa M, Imai S, Wakiguchi $\mathrm{H}$, Saito $\mathrm{H}$, Matsumoto K: Corticosteroid and cytokines synergistically enhance toll-like receptor 2 expression in respiratory epithelial cells. Am J Respir Crit Care Med 2004, 31:463-469.

31. MacRedmond RE, Greene CM, Dorscheid DR, McElvaney NG, O'Neill SJ: Epithelial expression of TLR4 is modulated in COPD and by steroids, salmeterol and cigarette smoke. Resp Res 2007, 8:84.

32. Borchers MT, Wesselkamper SC, Curull V, Ramirez-Sarmiento A, Sanchez-Fon A, Garcia-Aymerich J, Coronell C, Lloreta J, Agusti AG, Gea J, et al: Sustained CTL activation by murine pulmonary epithelial cells promotes the development of COPD-like disease. J Clin Invest 2009, 119:636-649.

33. Lee SH, Goswami S, Grudo A, Song LZ, Bandi V, Goodnight-White S, Green L, Hacken-Bitar J, Huh J, Bakaeen F, et al: Antielastin autoimmunity in tobacco smoking-induced emphysema. Nat Med 2007, 13:567-569.

34. Grumelli S, Corry DB, Song LZ, Song L, Green L, Huh J, Hacken J, Espada R, Bag R, Lewis DE, Kheradmand F: An immune basis for lung parenchymal destruction in chronic obstructive pulmonary disease and emphysema. PLoS Med 2004, 1:e8

35. Barcelo B, Pons J, Ferrer JM, Sauleda J, Fuster A, Agusti AG: Phenotypic characterisation of T-lymphocytes in COPD: abnormal CD4 + CD25+ regulatory T-lymphocyte response to tobacco smoking. Eur Respir J 2008, 31:555-562

36. Cosio MG, Saetta M, Agusti A: Immunologic aspects of chronic obstructive pulmonary disease. Eur J Immunol 2009, 360:2445-2454.

37. van der Strate BW, Postma DS, Brandsma CA, Melgert BN, Luinge MA, Geerlings M, Hylkema MN, van den Berg A, Timens W, Kerstjens HA: Cigarette smoke-induced emphysema: A role for the B cell? Am J Respir Crit Care Med 2006, 173:751-758.

38. Asprodites N, Zheng L, Geng D, Velasco-Gonzalez C, Sanchez-Perez L, Davila E: Engagement of Toll-like receptor-2 on cytotoxic T-lymphocytes occurs in vivo and augments antitumor activity. FASEB J 2008, 22:3628-3637.

39. Punturieri A, Copper P, Polak T, Christensen PJ, Curtis JL: Conserved nontypeable Haemophilus influenzae-derived TLR2-binding lipopeptides synergize with IFN-beta to increase cytokine production by resident murine and human alveolar macrophages. J Immunol 2006, 177:673-680.

40. Sethi S: Infectious etiology of acute exacerbations of chronic bronchitis. Chest 2000, 117:380S-385S.

41. Murphy TF, Brauer AL, Schiffmacher AT, Sethi S: Persistent colonization by Haemophilus influenzae in chronic obstructive pulmonary disease. Am J Respir Crit Care Med 2004, 170:266-272.

42. van Schilfgaarde M, Eijk P, Regelink A, van Ulsen P, Everts V, Dankert J, van Alphen L: Haemophilus influenzae localized in epithelial cell layers is shielded from antibiotics and antibody-mediated bactericidal activity. Microb Pathog 1999, 26:249-262.

43. Craig JE, Cliffe A, Garnett K, High NJ: Survival of nontypeable Haemophilus influenzae in macrophages. FEMS Microbiol Lett 2001, 203:55-61.

44. King PT, Lim S, Pick A, Ngui J, Prodanovic Z, Downey W, Choong C, Kelman A, Baranyai E, Francis $M$, et al: Lung T-cell responses to nontypeable Haemophilus influenzae in patients with chronic obstructive pulmonary disease. J Allergy Clin Immun 2012, In press.

45. Wang Z, Zheng T, Zhu Z, Homer RJ, Riese RJ, Chapman HA Jr, Shapiro SD, Elias JA: Interferon gamma induction of pulmonary emphysema in the adult murine lung. J Exp Med 2000, 192:1587-1600.

46. Churg A, Dai J, Tai H, Xie C, Wright JL: Tumor necrosis factor-alpha is central to acute cigarette smoke-induced inflammation and connective tissue breakdown. Am J Respir Crit Care Med 2002, 166:849-854

47. Churg A, Wang RD, Tai H, Wang X, Xie C, Dai J, Shapiro SD, Wright JL: Macrophage metalloelastase mediates acute cigarette smoke-induced inflammation via tumor necrosis factor-alpha release. Am J Respir Crit Care Med 2003, 167:1083-1089.

48. Churg A, Wang RD, Tai H, Wang X, Xie C, Wright JL: Tumor necrosis factoralpha drives $70 \%$ of cigarette smoke-induced emphysema in the mouse. Am J Respir Crit Care Med 2004, 170:492-498.

49. Saetta M, Di Stefano A, Turato G, Facchini FM, Corbino L, Mapp CE, Maestrelli P, Ciaccia A, Fabbri LM: CD8+ T-lymphocytes in peripheral airways of smokers with chronic obstructive pulmonary disease. Am J Respir Crit Care Med 1998, 157:822-826.

50. Rahman AH, Cui W, Larosa DF, Taylor DK, Zhang J, Goldstein DR, Wherry EJ, Kaech SM, Turka LA: MyD88 plays a critical T cell-intrinsic role in supporting CD8 T cell expansion during acute lymphocytic choriomeningitis virus infection. J Immunol 2008, 181:3804-3810.

51. Rahman AH, Taylor DK, Turka LA: The contribution of direct TLR signaling to T cell responses. Immunol Res 2009, 45:25-36.

doi:10.1186/1465-9921-14-13

Cite this article as: Freeman et al.: Lung CD8+ T cells in COPD have increased expression of bacterial TLRs. Respiratory Research 2013 14:13.

\section{Submit your next manuscript to BioMed Central and take full advantage of:}

- Convenient online submission

- Thorough peer review

- No space constraints or color figure charges

- Immediate publication on acceptance

- Inclusion in PubMed, CAS, Scopus and Google Scholar

- Research which is freely available for redistribution

Submit your manuscript at www.biomedcentral.com/submit
C) Biomed Central 